\title{
An analytical solution of the cable equation predicts the frequency preference of a passive non-uniform cylindrical cable in response to extracellular oscillating electrical fields
}

\author{
Hiromu Monai*1, Toshiaki Omori2,4, Masato Okada2,4, Masashi Inoue ${ }^{3}$, \\ Hiroyoshi Miyakawa ${ }^{3}$ and Toru Aonishi ${ }^{1,4}$
}

Address: ${ }^{1}$ Dep. of Computational Intelligence and System Science, Tokyo Tech., Yokohama, 2268502, Japan, ${ }^{2}$ Dep. of Complexity Science and Engineering, Univ. of Tokyo, Kashiwa, 2778561, Japan, ${ }^{3}$ Dep. of Life Science, Tokyo Univ. of Pharmacy and Life Science, Hachioji, 1920392, Japan and ${ }^{4}$ Brain Science Institute, RIKEN, Wako, 3510198, Japan

Email: Hiromu Monai* - monai@acs.dis.titech.ac.jp

* Corresponding author

from Eighteenth Annual Computational Neuroscience Meeting: CNS*2009

Berlin, Germany. 18-23 July 2009

Published: 13 July 2009

BMC Neuroscience 2009, 10(Suppl I):P38 doi:10.1 I86/I47I-2202-I0-SI-P38

This abstract is available from: http://www.biomedcentral.com/I47I-2202/I0/SI/P38

(c) 2009 Monai et al; licensee BioMed Central Ltd.

Under physiological and artificial conditions, the dendrites of neurons can be exposed to electrical fields [1-3]. Recent experimental studies suggested that the membrane resistivity of the distal apical dendrites of cortical and hippocampal pyramidal neurons may be significantly lower than those of the proximal dendrites and the soma [4-6]. To understand the behavior of dendrites in time varying extracellular electrical fields, we obtained analytical solutions of the cable equation for finite cylindrical cables with and without a leak conductance at one end by employing the Green's function method. The solution of a cable with leak at one end for DC electrical fields shows a reversal of polarization at the leaky end (Figure 1), as has been shown previously by employing the method of variable separation and Fourier expansion [7]. The solution of a cable with leak at one end for AC electrical fields shows that the leaky end has a frequency preference in the response amplitude (Figure 2).

Our results suggest that a passive dendrite with low resistivity at the distal end would show a frequency preference in response to sinusoidal extracellular local field potentials. The Green's function obtained in our study can be used to calculate response for any form of extracellular electrical field.

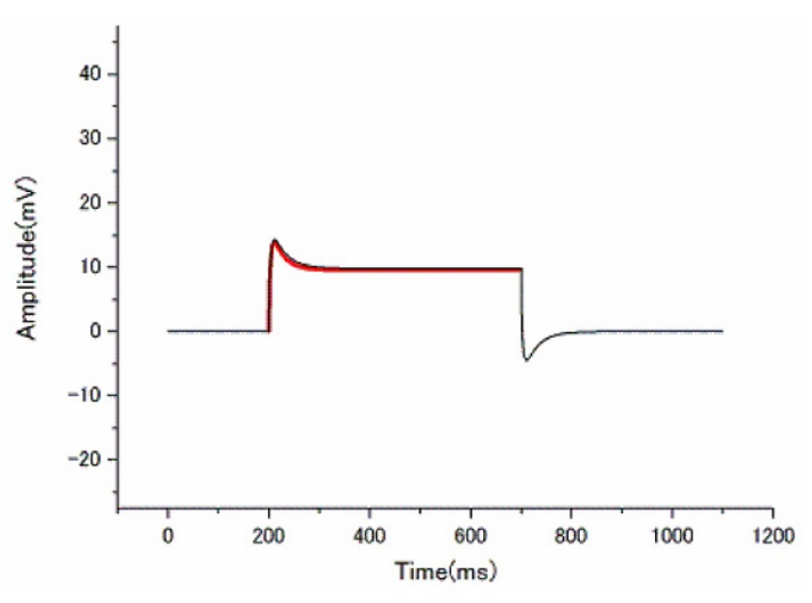

Figure I

Response to extracellular DC fields. The black line is a numerical solution of the cable equation by using the implicit method, and the red line is a theoretical solution by using the Green's function method. The theoretical solution shows slower hyperpolarization after rapid depolarization, i.e., a biphasic change. 

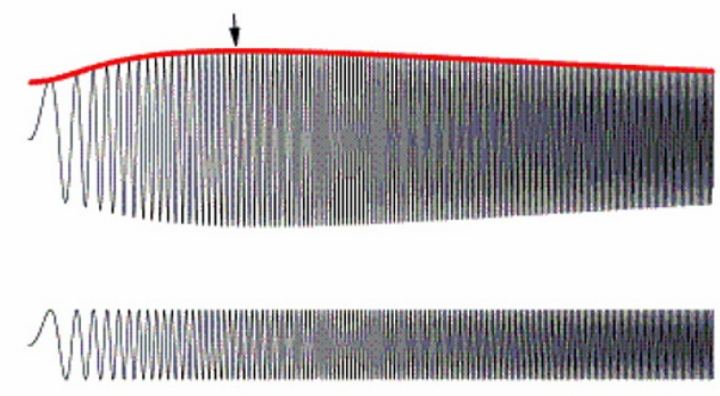

$\begin{array}{cccccc}1 & 1 & 1 & 1 & 1 \\ 0 & 10 & 20 & 30 & 40 & 50 \\ & \text { Frequency }(\mathrm{Hz})\end{array}$

\section{Figure 2}

Response to extracellular AC fields. By applying an AC field with a linearly changing frequency (below), the numerically obtained amplitude of the $A C$ responses (black line) was maximized at a certain frequency, i.e., frequency preference (Arrow). The red line denotes the amplitude of the theoretical solution.

\section{References}

I. Bikson M, et al.: Effects of uniform extracellular DC electrical fields on excitability in rat hippocampal slices in vitro. J Physiol 2004, 557:175-195.

2. Faber DS, Korn H: Electrical Field Effects: Their relevance in central neural networks. Physiol Review 1989, 69:821-863.

3. Jefferys JGR: Nonsynaptic modulation of neuronal activity in the brain: Electric currents and extracellular ions. Physiol Review 1995, 75:689-723.

4. Inoue M, et al:: Dendritic attenuation of synaptic potentials in the CAI region of rat hippocampal slices detected with an optical method. Eur J Neurosci 200I, I3:171I-172I.

5. Omori T, et al:: Estimated Distribution of Specific Membrane Resistance in Hippocampal CAI Pyramidal Neuron. Brain Research 2006, I I 25: 199-208.

6. Stuart G, Spruston N: Determinants of voltage attenuation in neocortical pyramidal neuron dendrites. J Neurosci 1998, I 8:350I-35I0

7. Svirskis G, et al:: Detection of a Membrane Shunt by DC Field Polarization during Intracellular and Whole Cell Recording. J Neurophysiol 1997, 77:579-586.
Publish with Bio Med Central and every scientist can read your work free of charge

"BioMed Central will be the most significant development for disseminating the results of biomedical research in our lifetime. "

Sir Paul Nurse, Cancer Research UK

Your research papers will be:

- available free of charge to the entire biomedical community

- peer reviewed and published immediately upon acceptance

- cited in PubMed and archived on PubMed Central

- yours - you keep the copyright
BioMedcentral 